\title{
Effect of Vitamin D on Paclitaxel Efficacy in Triple-negative Breast Cancer Cell Lines
}

\author{
CATHERINE A. WILHELM, ZACKARY J. CLOR and JESSICA L. KELTS
}

Department of Chemistry and Biochemistry, University of Michigan-Flint, Flint, MI, U.S.A.

\begin{abstract}
Background/Aim: Triple-negative breast cancer $(T N B C)$ is a highly aggressive breast cancer that disproportionately affects women with darker skin and is often treated with paclitaxel (PTX). Here, the effect of vitamin D on p53-positive DU4475 cells and its ability to decrease the $I C_{50}$ of PTX in these cells were investigated. Materials and Methods: The growth inhibitory effects of vitamin D on DU4475 cells and the effect of PTX plus vitamin $D$ on overall TNBC cell viability was assessed using CellTiter-Glo ${ }^{\circledR}$. Results: Vitamin D increased proliferation of DU4475 cells at low concentrations and lowered the $I C_{50}$ of PTX. However, it did not change the $I_{50}$ of PTX in MDA$M B-231$ cells which remained largely viable. Conclusion: The effect of vitamin $D$ on DU4475 cell viability was different than in other TNBC cells. The effect of PTX on DU4475 cells was enhanced with vitamin D. MDA-MB-231 cells were relatively resistant to the effects of PTX.
\end{abstract}

Triple-negative breast cancer (TNBC) is characterized by the lack of estrogen receptor, progesterone receptor, and human epidermal growth factor receptor 2 (Her2) amplification and accounts for $15-20 \%$ of all breast cancers $(1,2)$. As it lacks these receptors, TNBC is unresponsive to endocrine chemotherapies like tamoxifen and anti-Her2 pharmacotherapies like herceptin. As a result, TNBC is often treated with non-specific chemotherapy agents such as taxanes (paclitaxel (PTX) or docetaxel) in combination with anthracyclines or platinum chemotherapeutic drugs $(3,4)$. TNBC is an aggressive form of cancer that, when compared to other types of breast cancer, shows increased mortality and increased rates of recurrence in the first five years $(5$, 6). Paradoxically, TNBC shows an increased pathologic

Correspondence to: Dr. Jessica Lynn Kelts, Ph.D., University of Michigan-Flint, Department of Chemistry and Biochemistry, 303 E. Kearsley St., MSB 556, Flint, MI 48502, U.S.A. Tel: +1 8107623218, e-mail: jkelts@umflint.edu

Key Words: Breast cancer, triple-negative breast cancer, vitamin D, paclitaxel. complete response (PCR) to chemotherapy compared to other cancers, but patients that don't achieve initial PCR have a much higher 5-year mortality rate than patients with other types of cancer $(4,6)$.

In addition to having a poor prognosis and being difficult to treat, TNBC has been shown to disproportionately affect African-American women over Caucasian women (7-9). This disparity in the prevalence of TNBC mirrors the difference in vitamin D levels between Caucasian and non-Caucasian women $(10,11)$. Some studies have shown a connection between vitamin D deficiency and the triple-negative phenotype in breast cancer (12). A recent study found that expression of the vitamin D receptor (VDR) in TNBC resulted in 26 months longer survival than patients without VDR, supporting the hypothesis that vitamin D pathways could serve as targets for treatment of TNBC (13). Another recent study indicated the use of vitamin $\mathrm{D}$ and a vitamin $\mathrm{D}$ analog as a possible preventative strategy for TNBC (14). These studies suggested that vitamin $\mathrm{D}$ may be important for the prevention, treatment, and survival of TNBC. It has also been theorized that the anti-proliferative vitamin $\mathrm{D}$ effect in cancers may depend on the presence of wild-type, not mutated, p53 protein (15).

It has previously been shown that vitamin $\mathrm{D}$ can increase the effectiveness of cancer drugs, including PTX. Wang et al. showed that 1,25-dihydroxyvitamin $\mathrm{D}_{3}(1,25 \mathrm{D} 3)$ could sensitize MDA-MB-231, a triple-negative breast cancer cell line, to PTX (16). Other studies indicated increased potency of PTX when combined with vitamin D in endometrial (17), prostate and murine squamous cell carcinoma (18), and thyroid (19) cancer cell lines. Taken together, these studies show that there may be a role for vitamin $D$ in chemotherapeutic protocols. At minimum, doctors may want to ensure patients are not vitamin D deficient.

In this study, the effect of 25-hydroxyvitamin $\mathrm{D}_{3}(25-\mathrm{OH})$ and 1,25D3 on DU4475 cell proliferation was characterized. As DU4475 is a wild-type p53-positive TNBC cell line, it was examined whether vitamin $\mathrm{D}$ compounds show antiproliferative effects rather than the proliferative effect or absence of effect observed with TNBC lines expressing mutant p53 or lacking p53 (20). It was also investigated 
whether low levels of either vitamin D compound increased the potency of PTX in DU4475 and MDA-MB-231 cells.

\section{Materials and Methods}

Materials. MDA-MB-231 and DU4475 cells were purchased from ATCC (American Tissue Culture Collection, Manassas, VA, USA). All cell culture reagents were purchased through Thermo Fisher Scientific (Waltham, MA, USA). Fetal bovine serum (FBS) was from Gibco (Thermo Fisher Scientific). Qualified, heatinactivated serum was used to maintain cell lines and charcoal stripped serum was used for vitamin D studies. 25hydroxyvitamin D3, 1,25-dihydroxyvitamin D3 and paclitaxel were purchased from Sigma (St. Louis, MO, USA). The vitamin D compounds were diluted to $1 \mathrm{mM}$ in ethanol and PTX was diluted to $10 \mathrm{mM}$ in DMSO. CellTiter-Glo ${ }^{\circledR}$ was purchased from Promega (Madison, WI, USA).

Cell lines and culture conditions. DU4475 cells were maintained in Roswell Park Memorial Institute 1640 media containing GlutaMAX (RPMI 1640), 20\% heat-inactivated fetal bovine serum (FBS), $100 \mathrm{U} / \mathrm{ml}$ penicillin, $100 \mu \mathrm{g} / \mathrm{ml}$ streptomycin, $0.25 \mu \mathrm{g} / \mathrm{ml}$ Fungizone ${ }^{\circledR}$, and $1 \mathrm{mM}$ sodium pyruvate. Cells were split to 250,000 cells $/ \mathrm{ml}$ three times per week by pelleting the cells at 250 $\mathrm{x} g$ for $5 \mathrm{~min}$, resuspending in new media, and transferring to the cell culture treated flasks or plates. MDA-MB-231 cells were maintained in minimal essential media (MEM) containing $10 \%$ heat-inactivated FBS, $1 \mathrm{mM}$ GlutaMAX, $100 \mathrm{U} / \mathrm{ml}$ penicillin, 100 $\mu \mathrm{g} / \mathrm{ml}$ streptomycin, $0.25 \mu \mathrm{g} / \mathrm{ml}$ Fungizone ${ }^{\circledR}$, and $1 \mathrm{mM}$ sodium pyruvate. They were passaged twice per week using $0.25 \%$ Trypsin-EDTA.

Effect of vitamin D on cell growth. DU4475 cells were plated at a density of 1,000 cells per well in a volume of $70 \mu \mathrm{l}$ of media prepared with stripped serum the day before treatment in clear 96well plates. Cells were incubated overnight at $37^{\circ} \mathrm{C}$ in a $5 \% \mathrm{CO}_{2}$ incubator to match the attachment period used by Richards et al. (20). The next day, $10 \mu \mathrm{l}$ of vitamin D were added to each well. The final concentration of vitamin $\mathrm{D}$ in the plate ranged from $0-1,000$ $\mathrm{nM}$ and the concentration of ethanol vehicle was constant at $0.1 \%$. The plates incubated for $72 \mathrm{~h}$. At that time, the number of live cells in each well was measured using the CellTiter-Glo ${ }^{\circledR}$ luminescent assay as directed by the manufacturer. Briefly, $80 \mu \mathrm{l}$ of reconstituted assay reagent was added to each well. The plate was agitated for 2 min on a plate shaker and incubated at room temperature for 20 min. Eighty $\mu \mathrm{l}$ of the mixture were then aliquoted to a white luminometer plate and measured on a Promega GloMax ${ }^{\circledR}$ Multi Detection System luminometer. Measurements were determined in quadruplicate on each plate and three biological replicates were run for the cell line.

Effect of vitamin $D$ on paclitaxel treatment. Cells were plated in clear, cell culture treated, 96-well plates at a density of 1,000 cells per well in a volume of $70 \mu \mathrm{l}$ in media containing stripped serum. In some experiments, vitamin D was added concurrently with PTX and in others, it was added $24 \mathrm{~h}$ prior. Cells were treated with vehicle or $20 \mathrm{nM} 25-\mathrm{OH}$ or $1,25 \mathrm{D}_{3}$ and with $0.001-1.667 \mathrm{nM}$ PTX for 3 or 5 days. The concentration of DMSO was $0.1 \%$ and that of ethanol was $0.001 \%$. After the PTX treatment, CellTiter-Glo ${ }^{\circledR}$ was added to each well, using the same volume as the liquid in the well,

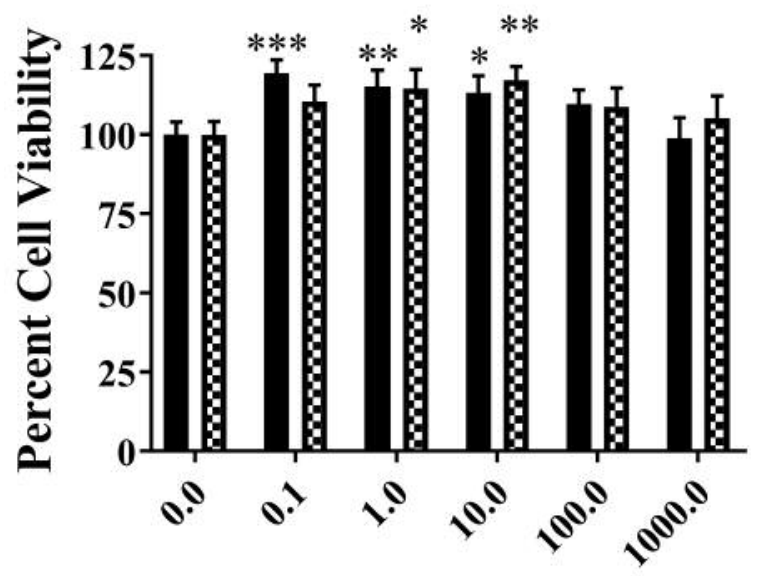

[Vitamin D], nM

Figure 1. Effect of vitamin D treatment on growth of DU4475 cells. Black filled bars represent 25-OH and cross-hatched bars represent 1,25D3. Cells were treated with the indicated amounts of vitamin $D$ for $72 \mathrm{~h}$ and cell number was measured using CellTiter-Glo ${ }^{\circledR}$. Data expressed as percentages of the vehicle control. Data obtained from four biological replicates with quadruplicate points and presented as mean $\pm S E M$-Values were determined by the student's $t$-test against the vehicle control. $* p<0.05, * * p<0.01, * * * p<0.001$.

and the plates were agitated for $2 \mathrm{~min}$ on a plate shaker and incubated at room temperature for $20 \mathrm{~min}$. Eighty $\mu \mathrm{l}$ of the mixture were then aliquoted to a white luminometer plate and measured on a Promega GloMax ${ }^{\circledR}$ Multi Detection System luminometer. Measurements were determined in quadruplicate on each plate and three biological replicates were run for the cell line.

Statistical analysis. The data were graphed using the GraphPad Prism 7.04 software and are presented as the mean \pm standard error of the mean (SEM). Statistical analysis was also performed in GraphPad using the Student's $t$-test. Results with a $p$-value of 0.05 or less were considered statistically significant. For $\mathrm{IC}_{50}$ values, 95\% confidence ranges and the extra-sum-of-squares $\mathrm{F}$ test generated in GraphPad were used to determine if the values were significantly different from one another.

\section{Results}

Effect of Vitamin D treatment on DU4475 cell growth. The effects of increasing concentrations of both 25-OH and $1,25 \mathrm{D} 3$ on DU4475 cells are shown in Figure 1. Low concentrations of both vitamin D compounds caused an increase in the number of cells. With $25-\mathrm{OH}$, cell viability peaked at $119 \%$ at $0.1 \mathrm{nM}$ and dropped back to $98 \%$ viability at $1000 \mathrm{nM}$. With 1,25D3, cell viability was above $100 \%$ at all concentrations tested. Cell viability peaked at $117 \%$ at $10.0 \mathrm{nM} 1,25 \mathrm{D} 3$. The increase in cell viability was similar to our previous work with other TNBC cells, although none 

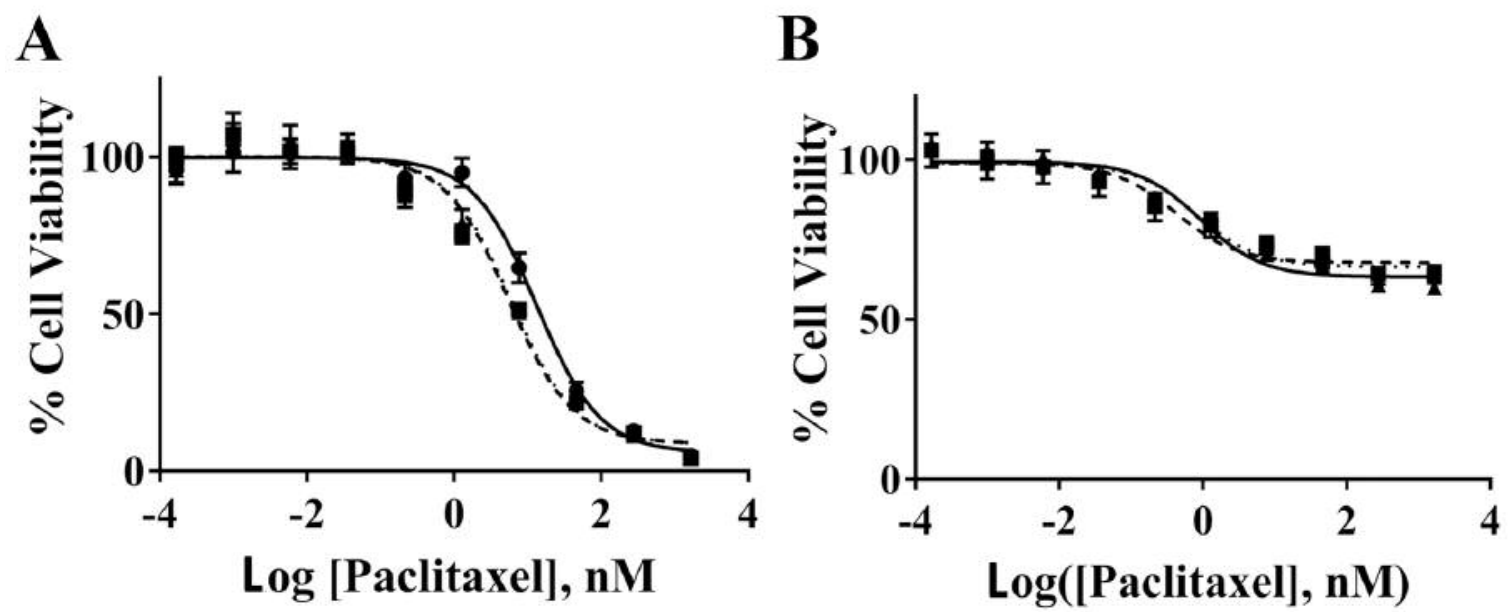

Figure 2. Effect of vitamin D on paclitaxel treatment of DU4475 (A) and MDA-MB-231 (B) cells cultured in media containing charcoal stripped serum. Filled circles and solid lines are vehicle control (ethanol), squares and dashed lines are 25-OH, and triangles and dotted lines are 1,25D3. Many symbols and lines overlap in this figure. Cells were treated with increasing amounts of PTX for $72 \mathrm{~h}$ in the presence of ethanol, 25-OH, or $1,25 D 3$ and cell viability measured using CellTiter-Glo ${ }^{\circledR}$. Data expressed as percentages of the top plateau of each curve (100\%). Data obtained from three biological replicates with quadruplicate points and presented as mean \pm SEM. Curve fitting performed with GraphPad Prism 7.04.

of them increased and then decreased in the same pattern as in DU4475 cells (20).

Effect of Vitamin D on paclitaxel treatment of DU4475 and MDA-MB-231 cells. When using DU4475 cells, the $\mathrm{IC}_{50}$ of the PTX was $13.2 \mathrm{nM}$ and after treatment with either form of vitamin $\mathrm{D}$, the $\mathrm{IC}_{50}$ was $5-6 \mathrm{nM}$ (Figure $2 \mathrm{~A}$ ). The $95 \%$ confidence intervals for these values did not overlap with the control. The $\log \mathrm{IC}_{50}$ values were compared to control using the extra-sum-of-square $\mathrm{F}$ test and $p$-values were $<0.005$. Therefore, the change in $\mathrm{IC}_{50}$, while small, is statistically significant. Vitamin D had no effect on the $\mathrm{IC}_{50}$ of PTX when regular serum was used (data not shown).

When using MDA-MB-231 cells, the bottom plateau of the curve did not approach zero (Figure 2B). Around 65\% of the cells remained viable at the highest concentrations of PTX. The $\mathrm{IC}_{50}$ was $0.4-0.9 \mathrm{nM}$ regardless of vitamin D treatment and neither was statistically different from control (Figure 2B). In both cell lines, $\mathrm{IC}_{50}$ values were higher when normal media were used as compared to stripped serum media. Also, MDA-MB-231 cell viability dropped to around $45 \%$ in normal serum conditions (data not shown).

Effect of vitamin D pre-treatment on paclitaxel potency. Cells were treated with vitamin D for 1 day and then with increasing amounts of PTX for 3 or 5 days. When pre-treated with vitamin D and then with PTX, DU4475 cells had a minimum cell viability of $25 \%$ after 3 days and $10 \%$ after 5 days (data not shown). After 3 days of PTX treatment, $\mathrm{IC}_{50}$ values were higher than those observed when vitamin $\mathrm{D}$ was
Table I. Effect of vitamin D pre-treatment on PTX potency in DU4475 and MDA-MB-231 cells. Cells were treated with increasing concentrations of PTX for either 3 or 5 days after 24-h pre-incubation with ethanol, 25-OH, or 1,25D3. Cell number was measured using CellTiter-Glo ${ }^{\circledR} . I C_{50}$ values were determined after fitting curves using GraphPad Prism 7.04 using three biological replicates with quadruplicate points. -Values were generated by GraphPad using the extra-sum-of-squares $F$ test to compare $\log _{50} C_{50}$ values between treatments and controls.

\begin{tabular}{|c|c|c|c|c|}
\hline & \multicolumn{2}{|c|}{ DU 4475} & \multicolumn{2}{|c|}{ MDA-MB-231 } \\
\hline & $\mathrm{IC}_{50}(\mathrm{nM})$ & $\begin{array}{l}p \text {-Value } \\
\text { LogIC }_{50}\end{array}$ & $\mathrm{IC}_{50}(\mathrm{nM})$ & $\begin{array}{l}p \text {-Value } \\
\text { LogIC }_{50}\end{array}$ \\
\hline \multicolumn{5}{|c|}{3 Day Paclitaxel } \\
\hline Ethanol & 27.5 & & 0.27 & \\
\hline $25-\mathrm{OH}$ & 23.2 & 0.447 & 1.21 & 0.069 \\
\hline $1,25 \mathrm{D} 3$ & 17.2 & 0.063 & 1.20 & 0.114 \\
\hline \multicolumn{5}{|c|}{5 Day Paclitaxel } \\
\hline Ethanol & 1.5 & & 0.020 & \\
\hline $25-\mathrm{OH}$ & 1.1 & 0.266 & 0.065 & 0.050 \\
\hline $1,25 \mathrm{D} 3$ & 1.1 & 0.325 & 0.16 & 0.003 \\
\hline
\end{tabular}

added concurrently (Table I). The $\mathrm{IC}_{50}$ value in the treatment with $1,25 \mathrm{D} 3$ was the lowest, but the $\log \mathrm{IC}_{50}$ was not significantly different from the control $(p=0.063)$. When the PTX treatment continued for 5 days, all $\mathrm{IC}_{50}$ values dropped to around $1 \mathrm{nM}$, regardless of vitamin $\mathrm{D}$ treatment. The $\mathrm{IC}_{50}$ values after 5 days of PTX treatment were far lower than those after 3-day treatments. 
When pre-treated with vitamin D and then with PTX for 3 or 5 days, MDA-MB-231 cells had a minimum cell viability of $70-80 \%$, indicating very little growth inhibition or cell death (data not shown). $\mathrm{IC}_{50}$ values were lower overall with pre-treatment (Table I). $\mathrm{IC}_{50}$ values with vitamin D pre-treatment displayed an upward trend compared to control. This was only statistically significant with $1,25 \mathrm{D} 3$ after 5 days.

\section{Discussion}

In our previous work, we had hypothesized that a lack of functional p53 may be responsible for the growth stimulation observed in TNBC cell lines (20). We explored this hypothesis by measuring the effect of increasing vitamin D concentrations using the DU4475 cell line, which is known to express wild-type p53 (21). In our previous work, two TNBC cell lines (MDA-MB-157 and MDA-MB468) showed a continuous increase in cell viability with increasing vitamin D concentrations, while MDA-MB-231 cells showed little difference in cell viability at any vitamin D concentration (20). The MCF-7 cell line, which expresses p53 and is not a TNBC line, showed no increase in cell viability with vitamin $\mathrm{D}$ treatment and demonstrated a decline in cell viability at high amounts of vitamin D (20). In this study, DU4475 cell growth was stimulated at very low concentrations of vitamin $\mathrm{D}$, but as concentration increased, especially above $10 \mathrm{nM}$, the cell viability fell back to $100 \%$. This pattern is different from that of the previously studied cell lines. It was previously reported that p53 was necessary for the anti-proliferative effects of vitamin $D$ which may explain why the increase in cell viability was reversed at high vitamin D concentrations (15). However, this would not explain the increase in cell viability at low concentrations of both $25-\mathrm{OH}$ and 1,25D3. The differential response to vitamin $\mathrm{D}$ treatment observed in these triple-negative cell lines is not unexpected, since there are many subclassifications of these cells $(22,23)$. DU4475 cell line is of the immunomodulatory type, MDAMB-468 is of the basal-like 1 type, and both MDA-MB-157 and MDA-MB-231 are of the mesenchymal stem-like type (22). These classifications alone are not enough to explain this vitamin $\mathrm{D}$ response, however, as we have previously found MDA-MB-231 and MDA-MB-157 cells have quite different vitamin $\mathrm{D}$ response despite belonging to the same class (20).

The effect of vitamin D on PTX efficacy in DU4475 was compared to MDA-MB-231 cells. PTX is a commonly used taxane in the treatment of triple negative breast cancer, usually in combination with other chemotherapy agents, such as platinum containing agents $(3,24)$. DU4475 cell line was studied as it is one of the few TNBC cell lines with a wildtype p53. MDA-MB-231 cell line was included due to a previous study showing a synergistic effect between vitamin $\mathrm{D}$ and PTX in that cell line (16). Not unexpectedly, no significant difference in $\mathrm{IC}_{50}$ values was observed when adding vitamin $\mathrm{D}$ to cells cultured in normal serum, as fetal bovine serum should already contain vitamin $\mathrm{D}$ as well as several other compounds removed by charcoal stripping. At $20 \mathrm{nM}$ vitamin $\mathrm{D}$, there was a small but significant downward shift of $\mathrm{IC}_{50}$ values in DU4475 cells with both forms of vitamin $\mathrm{D}$ when cultured in media containing charcoal stripped serum. When cells were pre-incubated with vitamin D and subsequently treated with PTX, this difference became not significant. When the PTX incubation was for 5 days after vitamin $\mathrm{D}$ pre-incubation, the $\mathrm{IC}_{50}$ values were much lower for both the control and vitamin D compounds and were not statistically different from one another. It would be interesting to investigate if that trend continues at higher concentrations of vitamin D.

There was no difference in response between vitamin $\mathrm{D}$ treated and untreated MDA-MB-231 cells and less than $50 \%$ residual viability was only attained using normal serum. There are apparently substances removed during the stripping of the media that help PTX to inhibit growth of MDA-MB-231 cells. This was exacerbated when cells were pre-incubated with vitamin D before a 3- or 5-day incubation with PTX, where, in some cases, cell viability remained at $80 \%$ at the highest PTX concentration. This verifies studies showing that MDA-MB-231 cells do not undergo apoptosis with PTX treatment (25), an issue that was apparently overcome at vitamin D levels higher than those used here (16). While lowering of the MDA-MB-231 PTX $\mathrm{IC}_{50}$ values was seen with longer PTX incubation and with vitamin D pre-incubation, it is doubtful that this is a meaningful result since viability was not significantly affected.

In conclusion, this study examined the effects of vitamin D compounds on the growth rate of DU4475 TNBC cells. DU4475 showed a vitamin D response pattern different from other TNBC lines and MCF-7 cells (20). At this point, it is unclear whether this is due to the lack of p53 in the other TNBC lines tested, to the fact that DU4475 belongs to a different subclass of TNBC cells or to some other reason. In addition, a slight, but statistically significant decrease of the PTX IC $_{50}$ was seen using both 25-OH and 1,25D3 at $20 \mathrm{nM}$ in DU4475 cells, but not in MDA-MB-231 cells, which respond less to PTX than DU4475. In the future, we would like to compare DU4475 to the only other known immunomodulatory TNBC cell line, HCC1187 (22). HCC1187 expresses mutated p53, so it could provide an informative comparison, as could experiments where DU4475 p53 expression is knocked-down using siRNA. Using these cells, vitamin $\mathrm{D}$ response patterns and the vitamin D effect on PTX $\mathrm{IC}_{50}$ could be investigated while eliminating the variability caused by using cells from a 
different subtype of TNBC. In this case, higher levels of vitamin $\mathrm{D}$ that mirror the mid to upper part of what is currently considered the normal range for $25-\mathrm{OH}(125-250 \mathrm{nM})$ could be used. Using cells from the same sub-type or modified versions of the same cell line can eliminate compound responses that differ between sub-types, as was the case for eribulin mesylate (23). It would be worthwhile to investigate if vitamin D has any effect on TNBC cells treated with combinations of chemotherapy drugs most often used in the clinic, like anthracyclines or platinum agents with PTX. Combinations of drugs would be chosen carefully, as some drug combinations have been shown to result in lower potency than one of the drugs alone (26).

\section{Acknowledgements}

The Authors would like to thank the Dr. Ben F. Bryer Foundation Medical Research Fund, the University of Michigan-Flint Research and Creative Activities Fund, and the UM-Flint Undergraduate Research Opportunity Program for funding this research.

\section{References}

1 Mayer IA, Abramson VG, Lehmann BD, and Pietenpol JA: New strategies for triple-negative breast cancer - deciphering the heterogeneity. Clin Cancer Res 20: 782-790, 2014.

2 Shastry $M$ and Yardley DA: Updates in the treatment of basal/triple-negative breast cancer. Curr Opin Obstet Gynecol 25: 40-48, 2013.

3 Yardley DA, Brufsky A, Coleman RE, Conte PF, Cortes J, Gluck S, Nabholtz JM, O'Shaughnessy J, Beck RM, Ko A, Renschler MF, Barton D, and Harbeck N: Phase II/III weekly nab-paclitaxel plus gemcitabine or carboplatin versus gemcitabine/carboplatin as first-line treatment of patients with metastatic triple-negative breast cancer (the tnAcity study): study protocol for a randomized controlled trial. Trials 16 : 575,2015 .

4 Huober J, von Minckwitz G, Denkert C, Tesch H, Weiss E, Zahm DM, Belau A, Khandan F, Hauschild M, Thomssen C, Hogel B, Darb-Esfahani S, Mehta K and Loibl S: Effect of neoadjuvant anthracycline-taxane-based chemotherapy in different biological breast cancer phenotypes: overall results from the GeparTrio study. Breast Cancer Res Treat 124: 133$140,2010$.

5 Dent R, Trudeau M, Pritchard KI, Hanna WM, Kahn HK, Sawka CA, Lickley LA, Rawlinson E, Sun P and Narod SA: Triplenegative breast cancer: clinical features and patterns of recurrence. Clin Cancer Res 13: 4429-4434, 2007.

6 Liedtke C, Mazouni C, Hess KR, Andre F, Tordai A, Mejia JA, Symmans WF, Gonzalez-Angulo AM, Hennessy B, Green M, Cristofanilli M, Hortobagyi GN and Pusztai L: Response to neoadjuvant therapy and long-term survival in patients with triple-negative breast cancer. J Clin Oncol 26: 1275-1281, 2008.

7 Brenton JD, Carey LA, Ahmed AA and Caldas C: Molecular classification and molecular forecasting of breast cancer: ready for clinical application? J Clin Oncol 23: 7350-7360, 2005 .
8 Harris LN, Broadwater G, Lin NU, Miron A, Schnitt SJ, Cowan D, Lara J, Bleiweiss I, Berry D, Ellis M, Hayes DF, Winer EP and Dressler L: Molecular subtypes of breast cancer in relation to paclitaxel response and outcomes in women with metastatic disease: results from CALGB 9342. Breast Cancer Res 8: R66, 2006.

9 Yao S and Ambrosone CB: Associations between vitamin D deficiency and risk of aggressive breast cancer in AfricanAmerican women. J Steroid Biochem Mol Biol 136: 337-341, 2013.

10 Tangpricha V, Pearce EN, Chen TC and Holick MF: Vitamin D insufficiency among free-living healthy young adults. Am J Med 112: 659-662, 2002.

11 Holick MF, Binkley NC, Bischoff-Ferrari HA, Gordon CM, Hanley DA, Heaney RP, Murad MH and Weaver CM: Evaluation, treatment, and prevention of vitamin D deficiency: an Endocrine Society clinical practice guideline. J Clin Endocrinol Metab 96: 1911-1930, 2011.

12 Rainville C, Khan Y and Tisman G: Triple negative breast cancer patients presenting with low serum vitamin D levels: a case series. Cases J 2: 8390, 2009.

13 Soljic M, Mrklic I, Tomic S, Omrcen T, Sutalo N, Bevanda M and Vrdoljak E: Prognostic value of vitamin D receptor and insulin-like growth factor receptor 1 expression in triple-negative breast cancer. J Clin Pathol 71: 34-39, 2018.

14 Shan NL, Wahler J, Lee HJ, Bak MJ, Gupta SD, Maehr H and Suh N: Vitamin D compounds inhibit cancer stem-like cells and induce differentiation in triple negative breast cancer. J Steroid Biochem Mol Biol 173: 122-129, 2017.

15 Stambolsky P, Tabach Y, Fontemaggi G, Weisz L, Maor-Aloni R, Siegfried Z, Shiff I, Kogan I, Shay M, Kalo E, Blandino G, Simon I, Oren M and Rotter V: Modulation of the vitamin D3 response by cancer-associated mutant p53. Cancer Cell 17: 273285, 2010.

16 Wang Q, Yang W, Uytingco MS, Christakos S and Wieder R: 1,25-Dihydroxyvitamin D3 and all-trans-retinoic acid sensitize breast cancer cells to chemotherapy-induced cell death. Cancer Res 60: 2040-2048, 2000

17 Kuittinen T, Rovio P, Staff S, Luukkaala T, Kallioniemi A, Grenman S, Laurila M and Maenpaa J: Paclitaxel, Carboplatin and 1,25-D3 Inhibit Proliferation of Endometrial Cancer Cells In Vitro. Anticancer Res 37: 6575-6581, 2017.

18 Hershberger PA, Yu WD, Modzelewski RA, Rueger RM, Johnson CS and Trump DL: Calcitriol (1,25-dihydroxycholecalciferol) enhances paclitaxel antitumor activity in vitro and in vivo and accelerates paclitaxel-induced apoptosis. Clin Cancer Res 7: 1043-1051, 2001.

19 Clinckspoor I, Verlinden L, Overbergh L, Korch C, Bouillon R, Mathieu C, Verstuyf A and Decallonne B: 1,25-dihydroxyvitamin D3 and a superagonistic analog in combination with paclitaxel or suberoylanilide hydroxamic acid have potent antiproliferative effects on anaplastic thyroid cancer. J Steroid Biochem Mol Biol 124: 1-9, 2011.

20 Richards SE, Weierstahl KA and Kelts JL: Vitamin D effect on growth and vitamin D metabolizing enzymes in triple-negative breast cancer. Anticancer Res 35: 805-810, 2015.

21 Chander H, Brien CD, Truesdell P, Watt K, Meens J, Schick C, Germain D and Craig AW: Toca-1 is suppressed by p53 to limit breast cancer cell invasion and tumor metastasis. Breast Cancer Res 16: 3413, 2014. 
22 Lehmann BD, Bauer JA, Chen X, Sanders ME, Chakravarthy AB, Shyr Y and Pietenpol JA: Identification of human triplenegative breast cancer subtypes and preclinical models for selection of targeted therapies. J Clin Invest 121: 2750-2767, 2011.

23 Brautigam K, Mitzlaff K, Uebel L, Koster F, Polack S, Pervan M, Steinert G, Rody A and Liedtke C: Subtypes of triplenegative breast cancer cell lines react differently to eribulin mesylate. Anticancer Res 36: 2759-2766, 2016.

24 Su S, Tian Y, Li Y, Ding Y, Ji T, Wu M, Wu Y and Nie G: "Triple-punch" strategy for triple negative breast cancer therapy with minimized drug dosage and improved antitumor efficacy. ACS Nano 9: 1367-1378, 2015.
25 Flores ML, Castilla C, Avila R, Ruiz-Borrego M, Saez C and Japon MA: Paclitaxel sensitivity of breast cancer cells requires efficient mitotic arrest and disruption of Bcl-xL/Bak interaction. Breast Cancer Res Treat 133: 917-928, 2012.

26 Tarpley M, Abdissa TT, Johnson GL and Scott JE: Bosutinib reduces the efficacy of Dasatinib in triple-negative breast cancer cell lines. Anticancer Res 34: 1629-1635, 2014.

Received July 24, 2018

Revised July 30, 2018

Accepted August 1, 2018 